\title{
Climatologists' patterns of conveying climate science to the agricultural community
}

\author{
Adam K. Wilke • Lois Wright Morton
}

Accepted: 26 May 2014/Published online: 7 August 2014

(C) The Author(s) 2014. This article is published with open access at Springerlink.com

\begin{abstract}
Climatologists have a unique role in providing various stakeholders and public data users with weather and climate information. In the north central region (NCR) of the United States, farmers, the agricultural sector, and policy makers are important audiences for climate science. As local and global climate conditions continue to shift and affect agricultural productivity, it is useful to understand how climatologists view their role as scientists, and how this influences their communication of climate science to agricultural stakeholders. In this study, data from interviews $(\mathrm{N}=13)$ and surveys $(\mathrm{N}=19)$ of state and extension climatologists in the NCR are analyzed to identify perceived roles and responsibilities as scientists and communicators. Pielke's (The honest broker: making sense of science in policy and politics, Cambridge University Press, Cambridge, 2007) framework of the idealized roles of scientists and their communication patterns are used to develop a typology of climate science communication. Findings reveal that more than half of climatologists perceive their role to provide information as pure scientists, while some engage in an arbiter role when requested. Fewer climatologists view their role as not only producing new knowledge, but also relating it to society and providing an expanded variety of alternative applications. Climatologists who perceive their role as simply providing information and letting data users interpret its application are missing an opportunity to reduce the gap between what scientists know and farmers believe. This suggests that if
\end{abstract}

\footnotetext{
A. K. Wilke $(\bowtie) \cdot$ L. W. Morton

Department of Sociology, Iowa State University, Ames,

IA 50014, USA

e-mail: awilke@iastate.edu

L. W. Morton

e-mail: 1wmorton@iastate.edu
}

climatologists would frame their climate science message in terms of agricultural impacts, hazard mitigation and risk management alternatives they could help the agricultural sector adapt to and mitigate environmental risks from a changing climate.

Keywords Climatologists - Agriculture - Climate science $\cdot$ Science communication $\cdot$ Science and society

\section{Introduction}

Climate science continues to be a contested and sharply partisan issue in the United States (US; Brulle et al. 2012; Leiswerowitz et al. 2012). Yet, the impacts of increasingly extreme weather events and variable climate conditions on agricultural productivity, particularly in the north central region (NCR) of the US, are well documented (i.e., Walthall et al. 2012). As farmers and agricultural stakeholders attempt to navigate the uncertainty and risks of changing long term weather and make good decisions for agricultural enterprises, they are challenged to sort through the different messages they receive from multiple sources: media, politicians, scientists, and advocacy/countermovement groups (Arbuckle et al. 2013b; Brulle et al. 2012).

Pielke (2007, p. 18) asserts that "sharply contested issues raise the political stakes and introduce dynamics quite different from issues which are less controversial." While Pielke is referencing science in public policy and politics, his observations have application at individual and local levels where science has a role as an information resource and the potential to offer a suite of alternatives to guide decision making. Communicating climate science in a contested environment, in a way that involves facts and values and informs decisions (Dietz 2013) is difficult at 
best and can be career threatening at worst (see Climategate, Leiswerowitz et al. 2012). Social and cultural factors, including perceptions of risk, are important in the willingness to accept climate change science and further complicate effective communication (Adger et al. 2009; Slimak and Dietz 2006).

In this highly charged environment, climatologists in the central US corn-belt region play important roles in providing region-specific scientific climate information to the agricultural community. Climatologists are trained to systematically detect complex atmospheric phenomenon using statistical methods to track and document patterns embedded in the random fluctuations of conditions in both stable and changing climates. Their role is publicly funded with expectations that their science will be made available to various sectors in support of individual, as well as local and state public decision making.

Public meanings of science are very applied and based in a subtle, more nuanced contextual interaction between physical and social factors (Fischer 2005). For example, although most sectors of the public observe and experience changes in weather, they often do not differentiate between climate and weather and do not accurately recall past climate conditions (Weber 2010). Even when scientific consensus is present, there is often disconnect among scientists, the public, and policymakers, as knowledge is regarded as negotiable (Innes 1994). Fischer (2005, p. 73) elaborates this by suggesting that the public considers many empirical truths as scientific opinion or belief derived from an "amalgam of technical and social judgments." It is these differences in expert and general public perceptions of climate science that underlie the unprecedented challenges agriculture faces in responding and adapting to changing climate patterns (Walthall et al. 2012).

US agriculture, producing $\$ 300$ billion a year in commodities, is vulnerable to climate change through direct effects on crop and livestock development and yields as well as indirect effects arising from changes in severity of pest pressure, availability of pollination services and the performance of water, soil, and other ecosystem services (Walthall et al. 2012). The 2012 USDA Climate Change and Agriculture in the United States, Bulletin 1935, well articulates scientific consensus on the need for adaptive and mitigative actions to manage the effects of a changing climate by altering patterns of agricultural activity to take advantage of emerging opportunities while minimizing the negative effects. But how can scientists help farmers, the value chain that supports them, and public decision makers that influence farm policy, internalize what is known and what is not known about climate science and give meaning to the consequences of different adaptation and mitigation strategies? Without some joint understanding of the problem and how to transform that information to apply to it their situation, it is unlikely that agreement on effective actions will be easily or quickly formulated (Innes 1994).

The climatologist, a central source of regional and localized climate information, is a critical actor in linking what is known about climate conditions such as temperature, precipitation, and unexpected variability to public policy and farmer responses. Both state and extension climatologists are tasked with assisting the public and policy makers from a broad variety of sectors. However, little is known about climatologists' interactions with agriculture and the roles they play in conveying and interpreting climate science. Further, better understanding of their roles could increase capacities to connect technical, social, and economic factors to the climate patterns they know so well and motivate individual and collective responses.

In this paper, we explore the diverse roles scientists assume in communicating their science and utilize a typology to understand the practical differences in how climatologists provide information and counsel to decision makers. Criteria are developed for assigning climatologists to one of four typologies proposed by Pielke (2007): pure scientist, issue advocate, science arbiter, and honest broker. Qualitative and quantitative data from interviews $(\mathrm{N}=13)$ and surveys $(\mathrm{N}=19)$ with state and extension climatologists from 11 states in the NCR of the United States are analyzed to obtain a deeper view of how climatologists' perceive their roles. In our results, climatologists' beliefs about climate change are presented, followed by an examination of climatologists' self-reflected roles and views on how they communicate their science. We conclude the paper by discussing the evolving roles of state and extension climatologists, negotiating boundaries between science and policy, and opportunities for scientists to provide a more accurate understanding of climate and the consequences of a variety of alternative adaptive responses.

Conveying scientific information and counsel to decision makers

The role of scientists in providing scientific information to assist with individual and collective decisions, including policy development, has been debated for centuries (Leshner 2003; Pielke 2007; Nelson and Vucetich 2009). A number of researchers find that the publics' perception of scientific consensus is a factor in the acceptance of science (Kahan et al. 2011b; Lewandowsky et al. 2012). These perceptions can affect whether societal action occurs to address climate-related issues and implement climate policy (Ding et al. 2011; Kahan et al. 2012; Rabinovich and Morton 2012). Recent public engagement with science and technology research (e.g. Holden 2002) utilizes theory 
based on the "deficit model," which assumes the public's lack of understanding of science is the barrier to acceptance.

However, it has been suggested that this may not adequately represent the various barriers of applying scientific knowledge to influence behaviors and obtain support for specific policies (Wynne 2006). Particularly in the case of climate science, a variety of complex social factors have been found to influence public reception and acceptance of scientific consensus, including values (Nilsson et al. 2004), emotions (Leiserowitz 2006), socially-reinforced perceptions (Kahan et al. 2011b), and mobilization by political parties and advocacy groups (Leiswerowitz et al. 2012). Further, there is evidence scientists have not well communicated scientific knowledge in ways that help resolve political divides and encourage effective decision making (Pielke 2007). Scientists often focus only on conveying the facts and rarely link them to alternative courses of action and the values of the decision maker (Dietz 2013). This connection is important, as Sturgis and Allum (2004, p. 67) acknowledge, "the effect of scientific knowledge on attitude toward science is not a straightforward linear main effect," and involves individual understandings and perceptions of science. Lach et al. (2003) articulate five roles for scientists in communicating information. These are reporting scientific results, interpreting scientific results, integrating results into decisions, advocating certain decisions, and actually making decisions. While Lach et al. (2003) do not make reference to a scientist who addresses a wide range of potential policy options, their study is important for understanding how perceived roles influence currently employed communication techniques. In their survey of scientists, other stakeholders, and the attentive public surrounding a topic of natural resource decision making, they found that the majority of each of these groups prefer that a scientist's role include integrating scientific results into management decisions (Lach et al. 2003).

Lackey (2007) provides further insights into the role of environmental and natural resource scientists in collective decision making. He declares that scientists should contribute to the decision making process, and that "this is not only the right thing to do, but [scientists] are also obligated to do so, especially if our work is funded by public resources" (Lackey 2007, p. 12). He goes on to warn, however, that scientists should be aware of and sensitive to the boundaries between scientific information and value judgments. Nelson and Vucetich (2009) review the role of scientists advocating certain decisions and find that connecting science to society is nearly unavoidable. They assert that scientists have a responsibility to connect scientific consensus to potential societal outcomes. However, they too warn that scientists must be completely aware of what constitutes appropriate advocacy to avoid personal judgments interacting with science during the process of providing information to the public.

Pielke (2007) observes that "scientists have choices about if, how, and when they decide to become actively engaged in policy." Further, "how such choices are made has consequences-for individuals, the scientific enterprise as a whole, and the broader society of which they are a part" (p. 135). To clarify the appropriateness of a scientist's choice to become engaged in connecting scientific consensus to society and decision making, Pielke has outlined four roles in which scientists may choose to convey information useful for decision making: pure scientist, science arbiter, issue advocate, and honest broker.

Pielke's four typologies and roles scientists assume

Pielke's (2007) pure scientist is focused on empirical facts and scientific truth derived from evidence-based data and confirmed or revised by ongoing research that asks questions and seeks answers. An underlying assumption is that a trained scientist has expertise that others do not have. The role of a scientist may be different depending on whom you ask, but more or less describes an individual who utilizes the scientific method to answer a question (Lehn 1998). Objective-fact based science is of greatest value in situations where the decision is highly specified and requires a clearly defined technical assessment. According to Pielke (2007), the pure scientist chooses to avoid interpretation of facts by limiting discussion of political implications and societal impacts of their research findings.

The science arbiter provides expert information to decision makers who have specific questions, but focuses on issues that are resolvable with science. In this regard, science arbiters are pure scientists who recognize there are political implications of their research findings, but do not advocate any particular stance or pursue the formation of outcome options. When policy makers request scientific information, scientists inform discussions with understandable and accurate information (Lackey 2007). The science arbiter is aware of the potential risk to credibility as a scientist, and as a result refrains from actively making connections between science and society, and instead responds to specific requests in an objective manner.

Issue advocates are scientists who have a sense of moral imperative beyond their science to actively align their viewpoints and research findings with specific social and political issues. Moral imperative refers to the perceived need for action or inaction on an issue thought to be critical to society (Wood 1999). In particular, it refers to a scientist who takes a position and actively advocates relevant climate science to induce specific action. Often the scientist is 
siding with a particular public policy agenda item, interest group, or even political party (Pielke 2007). In the case of climatologists, this may be manifested in public statements which advocate political intervention into issues involving atmospheric degradation, such as carbon tax.

The honest broker describes a scientist who acknowledges the influence of their research on individual and collective decision making, including public policy development. The honest broker not only considers and clarifies currently available options, but also identifies other possible options in light of scientific knowledge (Pielke 2007). As a result, they enlarge the range of current alternatives and enable individual and public decision makers to become informed of a larger set of possible positive, negative, and neutral outcomes. While doing so, honest brokers do not advocate one particular decision; instead they recognize and address the many possible outcomes based on their science and actively communicate these various scenarios. Scientists who practice this approach claim that separation between scientific facts and societal applications is inappropriate (Lubchenco 1998; Ehrlich 2000; Nelson and Vucetich 2009). This perspective assumes that scientists are first and foremost citizens, and as a result have a responsibility to make the public aware of what the science means to society (Kaiser 2000).

The roles of the climatologist

The appointment, funding, and location of the state climatologist varies by state with some directly employed by their state department of natural resources (DNR), department of conservation, or department of agriculture. For example, the state climatologist for Iowa is appointed by the secretary of agriculture and is located in the Iowa Department of Agriculture and Land Stewardship, and the Minnesota state climatologist is associated with the Minnesota Department of Natural Resources. Other state climatologists are faculty in their state's land grant university: the state climatologist for Ohio is located in the Department of Geography and Atmospheric Sciences at The Ohio State University; Indiana's state climatologist leads the state climate office from the Department of Agronomy at Purdue; the Illinois state climatologist is associated with the Water Center at University of Illinois; and the Missouri state climatologist is located at University of Missouri Climate Center but receives substantial support from the state DNR and Department of Conservation. Some states combine the state climatologist position with an extension position at the land grant university, such as South Dakota, where the state climatologist is faculty in the Department of Agriculture and Biosystems Engineering with an extension appointment also. Other land grant universities have extension climate scientists which are not officially appointed as state climatologists but similarly conduct climate science research and extend education to a variety of publics.

The call for a more engaged role of scientists in communicating their accumulating knowledge to the public (Marincola 2003; Friedman 2008; Meyer et al. 2010) presents a challenge to state and extension climatologists. The advocacy of public response and policy implementation to a particular scientific consensus can stretch the boundary role of publicly employed professionals and traditional land-grant university ideals as they attempt to carry out their extension and outreach roles in a non-partisan way (Bonnen 1998; Osmond et al. 2010). Many scientists recognize the delicate issue at hand and advise caution when extending scientific consensus to society and translating known facts derived from scientific experiments and observations into societal consequences, impacts and risks (Lach et al. 2003; Groffman et al. 2010; Wilhere 2011; Nelson and Vucetich 2009). A crucial aspect of the science and application relationship involves understanding the roles expert scientists can play in transforming climate data into practical, useful information that bridges the gulf between them and different publics.

A traditional role of the land grant university has been to provide applied agricultural information to the public via a community extension educator (Bonnen 1998). Today, extension agents provide current scientific information to the public on a large variety of topics, including agricultural engineering, agronomy, sociology, and climate. Extension climatologists are an important resource for the public, particularly agricultural producers, to obtain current and accurate climate information for their local region. These climatologists often also work as university researchers, which involves collecting and analyzing climate information to provide agricultural producers with forecast information to help with risk assessments and management decisions. State climatologists have a similar role of analyzing climate information and providing the public with relevant knowledge to assist in decisions. As publically funded positions, both extension and state climatologists are responsible for responding to requests for data from the public, including making information relevant to various sectors.

Understanding how these climate scientists perceive their roles in conveying science and how they transfer scientific information to data users can provide guidance for enhancing their capacities to better connect their science to the societal challenges of a changing climate. Specifically, in this research we ask, how do climatologists in the NCR perceive their roles in communicating climate science to the agricultural community? 


\section{Methods}

A mixed methods approach was utilized to answer the research question. Qualitative interviews $(\mathrm{N}=13)$ and quantitative surveys $(\mathrm{N}=19)$ were employed to document NCR climatologists' patterns of communicating climate science. A full universe of state and extension climatologists was compiled from the 12 state region. In some states, the state and extension climatologist were the same person, in others they held separate positions.

Qualitative interviews are well suited to exploratory research when there is a need to obtain a detailed and indepth picture of issues associated with a particular topic (Neuman 1994; Rubin and Rubin 1995). Interviews also allow the subject to insert and elaborate new ideas that lead to the development of emergent themes as well as provide the researcher the opportunity to better assess emphasis or hesitance in discussing certain topics (Denzin and Lincoln 1994). A quantitative mini-survey preceded the qualitative interviews, which included climatologist demographics and several items on beliefs and perceptions of climate change that were used to compare beliefs about climate change from a prior survey of upper Midwest farmer perceptions about agriculture and weather variability (see Arbuckle et al. 2013b). Specifically, climate change belief questions were drawn from a stratified random sample mail survey of 4,778 farmers ( $26 \%$ response rate) with at least US $\$ 100,000$ of gross sales and a minimum of 80 acres of corn production in 2011. Climatologists (like the farmers) were asked to select the statement that best reflected their beliefs about climate change with options including climate change is occurring or not, and causality can be attributed to natural, human, or some combination.

Climatologists were contacted by the researcher via e-mail with a request to participate in the study. Follow-up calls were also utilized when necessary to increase response rate. Participation in the study was voluntary, and all of the potential subjects contacted agreed to participate. Prior to the study, participants completed an informed consent form. Interview and survey content, study protocols, and informed consent documentation were approved prior to administration by [a land-grant University] Institutional Review Board (IRB) \#12-022.

Quantitative survey questions and qualitative interview questions were developed collectively by a committee of climate and social scientists. Specifically, the President of the American Association of State Climatologists, another State Climatologist, two professors of sociology, one climate scientist, two sociology graduate students, and the manager of a USDA climate project formed the committee. Several meetings of members of this group occurred for 3 months as the survey and interview instruments were developed and validated. Both instruments were pilot tested by a group of climate scientists to further ensure validity prior to implementation. The 13 climatologist interviews lasted on average about $90 \mathrm{~min}$, were audio recorded and occurred between March and May, 2012, with most of them in person and several taped phone interviews. There were 16 open-end questions revolving around four topics: connections and relationships among climatologists and farmers, techniques of communicating information, agricultural decision making based on climate information, and opportunities to assist agriculture utilizing climate information.

Interviews were transcribed and analyzed using NVivo qualitative data analysis software (NVivo 2009). Interviews were also read and hand-coded for themes and then discussed and reconciled by two independent reviewers. Eight key themes emerged: (1) objectivity, (2) agricultural management relevance, (3) agricultural economics and marketing, (4) agricultural decision timing, (5) location relevance, (6) format, (7) engagement, and (8) conservation management relevance. To further insure inter-rater reliability between the two coders of the interview transcripts, a qualitative analysis codebook was developed. Signal words for each theme were determined, and frequency of references to the themes was computed for each transcript. This codebook enabled researchers to quantify their coding of the themes, allowing for direct comparison among coders (MacQueen et al. 1998). Further, this codebook was used to compute inter-rater reliability on SPSS utilizing Cohen's kappa (Cohen 1960, 1968). For the eight themes analyzed, the Cohen's kappa was greater than 0.866. Two independent coders assessed each climatologist on the eight themes of the codebook to determine the spatial location represented in Fig. 1.

\section{Typology of climatologists}

Pielke's (2007) typology was used to develop criteria for analyzing the interview data to discover climatologists' perception of their roles. Idealized roles of climatologists (Table 1), defines four roles of scientists in society and then offers a representative quotation from the climatologists' interviews for each specific role type. Climatologists were assigned to an ideal type category based on definitions in Table 1 and corresponding data from interview and survey data that revealed evidence of their perceived roles. Then a scatterplot was created to visually represent the four patterns of science communication. Interview themes, survey data, and frequency of references to the eight themes were used to guide the spatial location for locating the climatologist on the scatterplot. The dominant communication pattern determined the scatterplot quadrant in which the climatologist was placed, however the more a climatologist evidenced traits of two or more ideal types, 
Fig. 1 Climatologists' perceived roles in communicating climate science: pure scientists, science arbiters, issue advocates, and honest brokers. More than half of climatologists perceive their role to be a pure scientist. A much smaller number link their science to a variety of applications

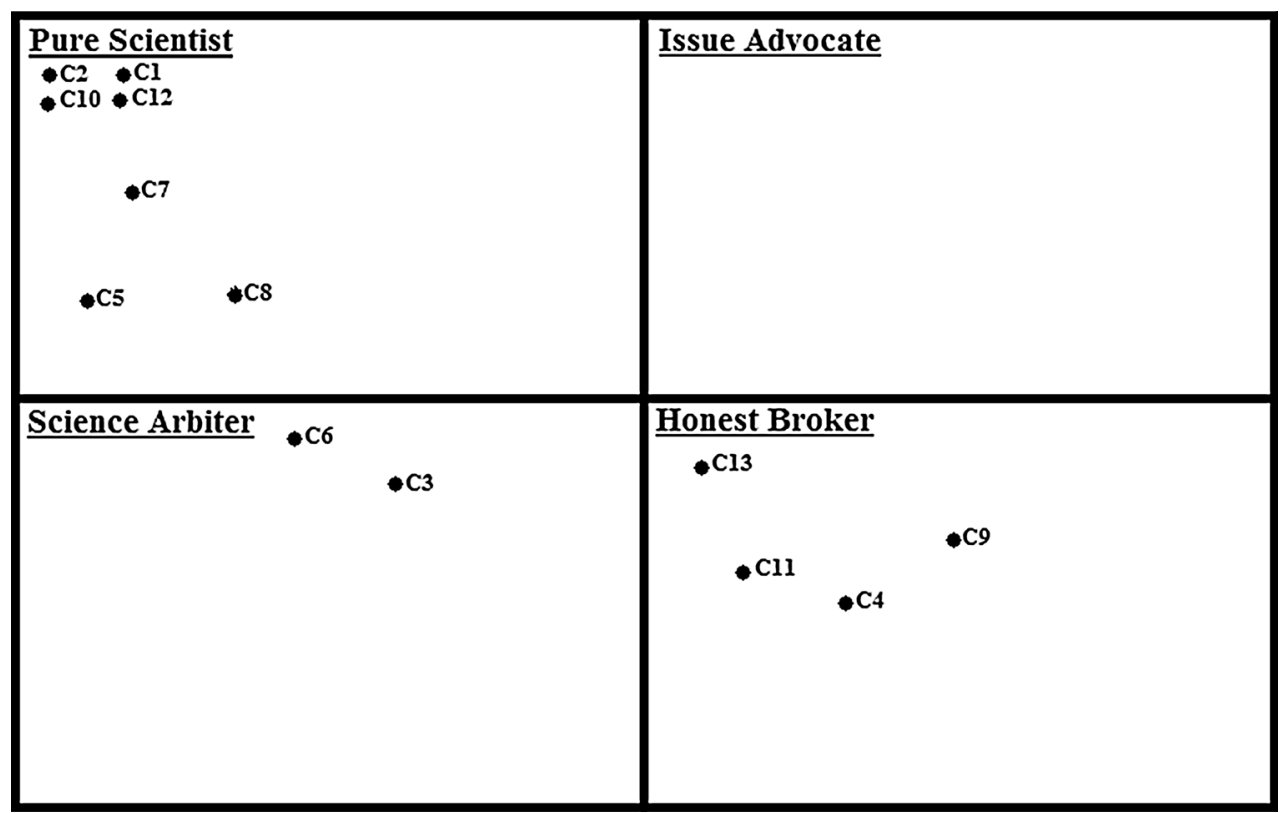

the closer they were located near the center. Likewise, the stronger they demonstrated traits of only one particular communication pattern, the closer they were to the respective corner of the scatterplot.

\section{Results}

Climate change is a fact, not a belief

Climate scientists and farmers have substantively different conceptions of what it means to have specific beliefs about climate change. In the interviews, several climatologists elaborated on the distinction between "beliefs" and "facts." For instance, "Prior to all this I wouldn't have had a problem with 'believe,' but with the fact that it's turned out to be such a political issue and believing this versus believing that," one climatologists stated. "It's not a belief," he continued. "It's not like believing in God or believing in ghosts or believing in Santa Claus. There's evidence, and you can ignore the evidence or not" (C2). Almost all the climatologists explicitly claimed that climate change is a fact, and not a belief.

Another climatologist elaborated, "And whether you believe in it just makes it too much like a religion and puts people on one side or the other. And I don't think that making people divide up into sides is...I just don't think that's the way to go. It's not the way to make progress" (C7). This statement reflects an assumption that in order for society to benefit from the application of climate science, diverse stakeholders must first accept that climate change has been established through scientific consensus, and must make the transition from subjective belief to scientific fact. To make progress in continually accumulating and applying currently available climate science, individual perceptions regarding environmental health and human risks established through socially referenced viewpoints (Kahan et al. 2011a) must be directly addressed.

Idealized roles of climatologists

Climatologists have a number of roles. For instance, they collect, document, and provide weather and climate information to public data users. Also, they make this information available to various stakeholders, which in the NCR, includes farmers and other agricultural stakeholders. "We worry about acquiring, archiving, and disseminating climate information," one climatologist stated, while also recognizing "the responsibility of outreach and sharing this information with the agricultural community" (C5).

When applying the idealized roles of scientists in society framework (Table 1) to the interview and survey data, more than half $(\mathrm{N}=7)$ of climatologists fall under the category of pure scientist (Fig. 1). Two of the climatologists explicitly referenced roles as science arbiter, providing climate science information upon request but not taking a position on the issue or policy decision. Four climatologists evidenced an honest broker role, combining their science knowledge with interpretations that informed consequences and different outcomes under different climate scenarios. It is particularly noteworthy that none of the 13 interviewees made any statements that could be interpreted as that of an issue advocate, thus that quadrant is empty. 
Table 1 Idealized roles of scientists in society, criteria for evaluation, and representative quotation from climatologists [adaptation of Pielke (2007)]

\begin{tabular}{|c|c|c|}
\hline $\begin{array}{l}\text { Role of } \\
\text { scientists in } \\
\text { society }\end{array}$ & $\begin{array}{l}\text { Criteria for evaluating climatologists based on their perceived role } \\
\text { of science in society }\end{array}$ & Representative quotation from climatologist \\
\hline $\begin{array}{l}\text { Pure } \\
\text { scientist }\end{array}$ & $\begin{array}{l}\text { Scientist focuses on objective facts only, perceiving that research } \\
\text { has no connection to policy and the utility or use of findings are } \\
\text { not relevant. Results of research are perceived as adding to } \\
\text { growing body of scientific knowledge, of which the public and } \\
\text { policy makers utilize in information societal, environmental, and } \\
\text { political decisions. Scientist simply performs research which is } \\
\text { placed in a repository and made available to all decision-makers }\end{array}$ & $\begin{array}{l}\text { I try to make it as apolitical as possible, nonpolitical, } \\
\text { apolitical and just show the facts, the data, the information } \\
\text { and let folks come up with their own decision or } \\
\text { assessment on what they think might be happening. C7 }\end{array}$ \\
\hline $\begin{array}{l}\text { Issue } \\
\text { advocate }\end{array}$ & $\begin{array}{l}\text { Scientist focuses research on a particular policy outcome or } \\
\text { political agenda. They accept that science is engaged with policy } \\
\text { makers, and attempt to participate in the process. They are } \\
\text { aligned with a particular stakeholder or interest group, and seek } \\
\text { to advance these specific interests by connecting scientific } \\
\text { outcomes with preferred policy and politics }\end{array}$ & Not present in interview transcripts \\
\hline $\begin{array}{l}\text { Science } \\
\text { arbiter }\end{array}$ & $\begin{array}{l}\text { Scientist is removed from overt connection of outcomes to policy } \\
\text { and politics, but does recognize that the public and policy } \\
\text { makers require expert input. Scientist accepts direct interaction } \\
\text { with policy makers, although stays focused on issues that may be } \\
\text { addressed by science. Focus is on positive questions that are } \\
\text { addressed from policy makers to scientists, and avoids } \\
\text { normative questions and interactions with stakeholders }\end{array}$ & $\begin{array}{l}\text { We need to have observations, we need to have better } \\
\text { forecasts, we need to have satellites-those are all things } \\
\text { that are noncontroversial-they're things we need to have } \\
\text { to protect our citizenry and protect our economic } \\
\text { livelihood. But when they become attached to climate by } \\
\text { any stretch, sometimes they become controversial. C3 }\end{array}$ \\
\hline $\begin{array}{l}\text { Honest } \\
\text { broker }\end{array}$ & $\begin{array}{l}\text { Scientist accepts connection of science to policy and politics, and } \\
\text { seeks to expand scope of options available to the policy makers. } \\
\text { They do so by integrating scientific knowledge with public and } \\
\text { stakeholders concerns. Similar to the science arbiter, this is often } \\
\text { in the form of a requested committee or assessment. Unlike the } \\
\text { issue advocates, they expand and clarify an expanded variety } \\
\text { potential options and outcomes }\end{array}$ & $\begin{array}{l}\text { We could produce some very likely scenarios that farmers } \\
\text { could evaluate and think about how they would respond to } \\
\text { these scenarios. We're not saying they're going to happen, } \\
\text { but these are plausible scenarios. C9 }\end{array}$ \\
\hline
\end{tabular}

In the interviews, many of the climatologists made direct comments regarding the disconnection between science and policy. This suggests they think that science is a linear process and experts simply offer knowledge that is then used by others. For instance, one climatologist remarked, "Where you get into big trouble is when you go beyond being a scientist and suddenly start advocating a particular policy. That's where you're apt to see a lot of your push back. So...I don't do any of the policy issues" (C1).

Many of the pure scientists mentioned a need for an advert separation from politics and strictly presentation and not interpretation of data. "I try to make it as apolitical as possible," one climatologist remarked, "and just show the facts, the data, the information and let folks come up with their own decision or assessment on what they think might be happening" (C3). Climatologists also generally framed their role in science as remaining neutral and not tailoring or directing research to address any particular outcome. "I first of all don't want to be considered an advocate for any particular agenda that people might have on either side of the issue. I don't vet to our customers, and climate skeptics will get the same service from me as someone who is concerned about climate change. We want to be always seen as an impartial deliverer of climate data, data that people can trust, and know it was not provided by somebody with an agenda" (C5).

A few climatologists even went so far as to reflect on the performance of their colleagues. "Some of the scientists have gotten so evangelical about this that they appear to have lost their objectivity." This climatologist continued this statement to support the viewpoint of the pure scientist, "Because they're promoting a position they're not letting the science speak for themselves; they're making an issue out of it beyond the basic science" (C2). Another climatologist referred to avoidance of connecting science to policy. "The other one that I do stay away from are policy issues" (C1). Descriptive norms are important in predicting a scientists' intention to participate in public engagement of science activities (Poliakoff and Webb 2007), and may influence the climatologists' apprehension to connect science with policy.

However, two climatologists that appeared to represent what is considered the science arbiter role were willing to make connections between science and society, particularly when requested. For instance, there was hesitance to actively 
relate scientific consensus to society impacts, however, there was acceptance that these connections may be necessary. "We need to have observations, we need to have better forecasts, we need to have satellites - those are all things that are noncontroversial - they're things we need to have to protect our citizenry and protect our economic livelihood. But when they become attached to climate by any stretch, sometimes they become controversial" (C6). These remarks came from an extension climatologist, whose role encompasses serving requests from public data users, as well as policy makers. In regards to their role as a scientist, he stated that, "We are truly people who are trying to help people understand what climate is, how climate varies, potential impacts of changes, and how things are going to change in the near and longer term" (C6).

There were also a few climatologists who could be considered in the idealized role of honest brokers of alternatives. For instance, one climatologist remarked, "Likely we as public citizens are going to have to make some really challenging decisions in the future - what, if anything, to do about climate change. We have to be informed. We have to be educated about those. We can't afford to be ignorant" (C9). It is important to understand that scientists are citizens first and foremost, and are equally affected by application of scientific consensus to decision making and policy development, or lack thereof. The classic role of the honest broker was illustrated in the statement:

So we could produce some very likely scenarios that farmers could evaluate and think about how they would respond to these scenarios. We're not saying they're going to happen, but these are plausible scenarios. So I think what farmers could do to adapt is to consider conditions outside the range of very recent experience, because there's going to be a higher likelihood... We have high confidence that there will be more of these conditions outside the range of recent experience $(\mathrm{C} 13)$.

There was recognition of climate science communication as requiring two kinds of education, showing past climate trends and how these patterns have changed the landscape.

We've made more and more effort in extension and with other groups to educate people and to show them the data and to show them the consequence of these changes. There's a twofold or two-pronged educational effort here. The first prong or the first path is to simply take the data and the history for a location and show how we are now measuring climate attributes that are outside the bounds of what we have measured historically. And we've got scads of examples of that. The second path or the second prong is to show what the consequence of that has been-how it has changed the landscape, how things are different than what they once were $(\mathrm{C} 4)$.

This two-pronged education approach seems to reflect the honest broker view of the interconnectedness between science and society. One aspect of the second prong of this approach was voiced by climatologists that thought one role was to demonstrate the wide variety of possible consequences of a changing climate while being mindful of the influence of social and cultural viewpoints that create diverse mental models among stakeholders. Their view was that the climate scientist should discuss environmental and social impacts associated with climate not in terms of regulation, pollution, or emissions, which it has most often been presented, but in terms of hazard and risk mitigation.

Climatologists thought this approach helped the farmer define the climate problem as one that presents a potential threat and assisted farmers in utilizing currently available science to help develop adaptive and mitigative management practices. This view supports the importance of framing, a technique of communication proposed by social and decision scientists which connects social problems identification to solutions and action (Nisbet and Mooney 2007).

Talk about it through hazard mitigation or early warning system for extreme events. That is the kind of thing that we need to move towards in terms of alerting the public or a particular sector that big things are coming or may be coming or may be more frequent than they used to be. That actually is a way into perhaps changing not only perception but also changing decisions (C11).

\section{Discussion}

Despite the contested nature of climate science, scientists remain by far the most trusted source of information on global warming (76 \%) according to a May 2011 survey of Americans (Leiswerowitz et al. 2012). A comparison (Table 2) of NCR climatologists survey responses and a 2012 random sample survey of corn-belt farmers whom they serve regarding beliefs about climate change (Arbuckle et al. 2013b) collaborates the qualitative differences found between the climate scientists and upper Midwestern farmers. For instance, while $53 \%$ of climatologists believe that climate change is occurring, and it is caused mostly by human activities, only $8 \%$ of farmers reported believing this statement. Further, $31 \%$ of farmers responded that there is not sufficient evident to know with certainty whether climate change is occurring on not, 
Table 2 Climatologists' and farmers' beliefs about climate change

$$
\begin{array}{ll}
\text { Climatologists } & \text { Farmers } \\
(\mathrm{N}=19)(\%) & (\mathrm{N}=4,778)
\end{array}
$$

(\%)

(a) Climate change is occurring,

5

25

and it is caused mostly by natural changes in the environment

(b) Climate change is occurring, 53 and it is caused mostly by human activities

(c) Climate change is occurring, 37 and it is caused more or less equally by natural changes in the environment and human activities

(d) Climate change is not occurring

(e) There is not sufficient evidence to know with certainty whether climate change is occurring or not

Findings for climatologists are from a 2012 survey of NCR state and extension climatologists; findings for farmers are from a 2012 random sample survey of NCR corn grain farmers (see Arbuckle et al. 2013b). The relevant question asked of both groups is as follows: There is increasing discussion about climate change and its potential impacts. Please select the statement that best reflects your beliefs about climate change. (Please circle one number.) The table presents a summary of climatologist and farmer responses

compared to only $5 \%$ of climatologists. None of the climatologists believe that climate change is not occurring, and only $3.5 \%$ of farmers reported believing this statement. Clearly this disconnect suggests a need for climatologists and farmers to improve their communication exchanges about the science of climate and how it can impact the agricultural landscape.

It is noteworthy that although all but one climatologist accepts climate change as occurring, there is no consensus on causality with $37 \%$ of climatologists attributing it to both natural changes in the environment and human activities compared to more than half claiming mostly human activities. Thus about a third of climatologists and farmers $(33 \%)$ agree that there are multiple causes of climate change suggesting opportunity to leverage common beliefs in approaching a discussion of climate science and what the data mean using an honest broker role.

The construction of four idealized roles of science in society provide a useful framework for understanding the message and underlying assumptions that influence the communication strategies used by climate scientists. Although more than half of the climatologists interviewed view their role as pure scientists, which entails mainly the duty of creating objective science, communication and social research indicates that it is also crucial for scientists to outline potential societal impacts associated with current knowledge (Nisbet and Mooney 2007). That is, society needs an honest broker that will provide both science and several interpretations as to what that science means and how it applies to individual and collective decision making, and society as a whole.

The observation by Weber (2010) that there is a substantive mismatch between climate scientists' and citizens' perceptions of how big a problem climate change is will not easily be resolved. However, state and extension climatologists have a role and opportunity to help the public, particularly farmers and the larger agricultural community whose livelihoods depend on adapting to changing weather and climate conditions, to better understand how to interpret and use the empirical facts they know so well. Our data suggest that too few climatologists are ready and willing to fill the role of honest brokers, by providing potential outcomes and options of societal response to scientific findings. Climatologists who perceive their role as simply providing information and letting data users interpret its application are missing an opportunity to reduce the gap between what scientists know and farmers believe. As science continues to develop adaptive management and mitigation techniques in response to hazards associated with changing climate patterns, it will be important to become aware of and outline potential options for how the public and policy-makers may interpret and respond to the science.

Scientists are increasingly expected by members of the public, policy-makers, and their colleagues to connect and apply their research to improving the health and wellbeing of society. Science is no longer perceived as separate from policy and politics, but as a necessary and valuable resource in informing complicated decisions that involve complex networks of stakeholders. Although there are barriers to engaging in policy, such as past negative experience, there are increasing incentives for connecting science to decision making (Singh et al. 2014). An important distinction has been made between "research science" and "policy science," or "trans-science" (Weinberg 1972, 1985). Fundamentally, this approach argues that as complexity and uncertainty of the scientific investigations increase, so does the democratization of how the science is conducted (Carolan 2006).

In other words, science proceeds in a more closed manner when uncertainty and complexity are low, but as complexity increases, such as in the case of environmental risks, scientific investigations become more normative and uncertain as social values come into play. Understanding potential environmental risks associated with climate change, for instance, increasingly requires scientists to address concepts such as "ecosystem health" which, Carolan (2006, p. 662) argues, is a value statement. Risk and impacts related to nature are generally regarded as subjective, and rest on individual beliefs about how we perceive what nature should be and what healthy is. It is well 
within the role of the climatologists to provide scientific contextualization to these complex factors and influence decision making by adequately translating available science for the benefit of the audience, and more importantly, society as a whole.

\section{Conclusion}

The climatologist is a scientist who empirically confirms data and produces climate science and considers these findings in absence of beliefs and attitudes about climate: they are factual. With more than half of our climate scientists falling into the pure scientist category, there is a sense of them being an incomplete resource as the public often does not realize the implications or understand effects of their information. This suggests there would be greater societal benefit if climatologists, as publicly paid employees, would utilize the honest broker role in discussing the patterns of change and different implications for individual and collective decision making. This role would not betray the factual and objective pursuit of science necessary to continue to detect and analyze complex weather and climate data, but would add value by offering explanations of how different climate scenarios-warmer temperatures, more precipitation, drought, changes in wind velocity and direction-may impact different agricultural production systems and practices.

Scientists, as trusted sources of climate information can play an important role in helping the public understand long term weather patterns, consequences and potential solutions to changing climate (Leiswerowitz et al. 2012). Changes in climate are generally slow and modifications of average climate conditions gradually occur over long time periods (Weber 2010), which has influenced public receptiveness on addressing the issue of climate change (Leiswerowitz et al. 2012). It has been documented that individual beliefs in scientific consensus (Lewandowsky et al. 2012), risk perceptions and beliefs (Leiserowitz 2006), and trust in information source (Rabinovich and Morton 2012; Maibach et al. 2011; Weber 2010) influence an individuals' willingness to become receptive to climate science information and utilize it in their decision making process. This is also evident in the agricultural sector, where it has been found that trust in information sources influences beliefs, and subsequently behaviors, about climate change (Arbuckle et al. 2013a).

In the process of providing scientific climate information to public data users, particularly the agriculture sector, state and extension climatologists are tasked with navigating the volatile social and political contexts which influence the reception and delivery of information. The role of providing objective and accurate information for individual decision making and public policy development encompasses the mission of public institutions. Because of the intense partisan battle over the issue of climate change, as well as media coverage and framing (Brulle et al. 2012), the role of the climatologists as a public servant providing information to assist in decision making may be differently interpreted between individual scientists, institutions, or agencies. However, there is an increasingly vocal group of citizens, scientists, and policy makers that claim an urgent need to apply current climate science knowledge to decision making and policy implementation. Climatologists could help society, and the agricultural sector in particular, by reconsidering their current patterns of communication, and recognizing their potential dual roles of proving scientific information and outlining impacts, hazards, and risks associated with currently available knowledge.

As indicated by our analysis and demonstrated in Fig. 1, climatologists vary in their location within each typology, suggesting that there are overlapping roles and behaviors that are likely to be context and situation specific. The context of agriculture is just one situation in which climatologists communicate information to public data users. Future research might explore alternative contexts of conveying information to determine if climatologists fall into the same idealized roles when working with different audiences. Some of the climatologists demonstrate characteristics of multiple idealized roles, which may be expressed more or less in various contexts. This study was limited to climatologists in the NCR, and may not well represent those in other regions of the United States. Future work could extend the empirical testing of the role of this scientist typology by examining all US climatologists and other climate scientists representing important agriculture regions of the world.

Acknowledgments This research funded in part by Iowa State University Agriculture and Home Economic Experiment Station; USDA-NIFA Climate Change, Mitigation, and Adaptation in Cornbased Cropping Systems (No. 2011-68002-30190) and USDA-NIFA Useful to Usable (U2): Transforming Climate Variability and Change Information for Cereal Crop Producers (No. 2011-68002-30220).

Open Access This article is distributed under the terms of the Creative Commons Attribution License which permits any use, distribution, and reproduction in any medium, provided the original author(s) and the source are credited.

\section{References}

Adger, W., S. Dessai, M. Goulden, M. Hulme, I. Lorenzoni, D. Nelson, L. Naess, J. Wolf, and A. Wrenford. 2009. Are there social limits to adaptation to climate change? Climatic Change 93: $335-354$.

Arbuckle, J., L.W. Morton, and J. Hobbs. 2013a. Understanding farmer perspectives on climate change adaptation and mitigation: The roles of trust in sources of climate information, climate 
change beliefs, and perceived risk. Environment and Behavior. doi:10.1177/0013916513503832. Accessed 1 June 2014.

Arbuckle, J.G., L. Prokopy, T. Haigh, J. Hobbs, T. Knoot, C. Knutson, A. Loy, A. Saylor Mase, J. McGuire, L. Wright Morton, J. Tyndall, and M. Widhalm. 2013b. Climate change beliefs, concerns, and attitudes toward adaptation and mitigation among farmers in the Midwestern United States. Climatic Change Letters 117(4): 943-950.

Bonnen, J.T. 1998. The land grant idea and the evolving outreach university. In University-community collaboration for the twenty-first century: Outreach to scholarship to youth and families, ed. R.M. Lerner, and L.A. Simon, 463-480. New York, NY: Garland Publishing.

Brulle, R., J. Carmichael, and C. Jenkins. 2012. Shifting public opinion on climate change: An empirical assessment of factors influencing concern over climate change in the U.S., 2002-2010. Climatic Change 114: 169-188.

Carolan, M. 2006. Science, expertise, and the democratization of the decision-making process. Society and Natural Resources 19: 661-668.

Cohen, J. 1960. A coefficient of agreement for nominal scales. Educational and Psychological Measurement 20(1): 37-46.

Cohen, J. 1968. Weighted kappa: Nominal scale agreement with provision for scaled disagreement or partial credit. Psychological Bulletin 70(4): 213-220.

Denzin, N., and Y. Lincoln. 1994. Handbook of qualitative research. Thousand Oaks, CA: Sage.

Dietz, T. 2013. Bring values and deliberation to science communication. PNAS 110(3): 14081-14087.

Ding, D., E.W. Maiback, X. Zhao, C. Roser-Renouf, and A. Leiserowitz. 2011. Support for climate policy and societal action are linked to perceptions about scientific agreement. Nature Climate Change 1: 462-466.

Ehrlich, P. 2000. Evolution of an advocate. Science 287: 2159.

Fischer, F. 2005. Citizens, experts, and the environment. Durham, NC: Duke University Press.

Friedman, D. 2008. Public outreach: A scientific imperative. Journal of Neuroscience 28: 11743-11745.

Groffman, P.M., C. Stylinksi, M.C. Nisbet, C.M. Duarte, R. Jordan, A. Burgin, M.A. Previtali, and J. Colosi. 2010. Restarting the conversation: Challenges at the interface between ecology and society. Frontiers in Ecology and the Environment 8(6): 284-291.

Holden, C. 2002. From PUS to PEST. Science 298(5591): 49.

Innes, J.W. 1994. Knowledge and public policy: The search for meaningful indicators. New Jersey: Transaction Publishers.

Kahan, D., E. Peters, M. Wittlin, P. Slovic, L. Ouellete, D. Braman, and G. Mandel. 2012. The polarizing impact of science literacy and numberacy on perceived climate change risks. Nature Climate Change 1547: 1-4.

Kahan, D.M., J. Gastil, D. Braman, and P. Slovic. 2011a. The cultural orientation of mass political opinion. Political Science and Politics 44(4): 711-714.

Kahan, D., H. Jenkins-Smith, and D. Braman. 2011b. Cultural cognition of scientific consensus. Journal of Risk Research 14(2): 147-174.

Kaiser, J. 2000. Ecologists on a mission to save the world. Science 287: $1188-1192$

Lach, D., P. List, B. Steel, and B. Shindler. 2003. Advocacy and credibility of ecological scientists in resource decisionmaking: A regional study. BioScience 53(2): 170-178.

Lackey, R. 2007. Science, scientists, and policy advocacy. Conservation Biology 21: 12-17.

Lehn, B. 1998. What is a scientist?. Minneapolis: Millbrook Press.

Leshner, A. 2003. Public engagement with science. Science 299(5609): 977.
Leiswerowitz, A., E. Maiback, C. Roser-Renouf, N. Smith, and E. Dawson. 2012. Climategate, public opinion, and the loss of trust. American Behavioral Scientist 57(6): 818-837.

Leiserowitz, A. 2006. Climate change risk perception and policy preferences: The role of affect, imagery, and values. Climatic Change 77(1-2): 45-72.

Lewandowsky, S., G. Gignac, and S. Vaughan. 2012. The pivotal role of perceived scientific consensus in acceptance of science. Nature Climate Change 1720: 1-6.

Lubchenco, J. 1998. Entering the century of the environment: A new social contract for science. Science 279: 491-497.

MacQueen, K.M., E. McLellan, K. Kay, and B. Milstein. 1998. Codebook development for team-based qualitative analysis. Cultural Anthropology Methods 10(2): 31-36.

Maibach, E., A. Leiserowitz, C. Roser-Renouf, and C. Mertz. 2011. Identifying like-minded audiences for global warming public engagement campaigns: An audience segmentation analysis and tool development. PLoS ONE 6(3): e17571.

Marincola, E. 2003. Research advocacy: Why every scientist should participate. PLoS Biology 1(3): 331-333.

Meyer, J., P. Frumhoff, S. Hamburg, and C. Rosa. 2010. Above the din but in the fray: Environmental scientists as effective advocates. Frontiers in Ecology and the Environment 8(6): 299-305.

Nelson, M., and J. Vucetich. 2009. On advocacy by environmental scientists: What, whether, why, and how. Conservation Biology 23: $1090-1101$.

Neuman, W. 1994. Social research methods: Qualitative and quantitative approaches, 2nd ed. Needham Heights, MA: Allyn and Bacon.

Nilsson, A., C. Borgstede, and A. Biel. 2004. Willingness to accept climate change strategies: The effect of values and norms. Journal of Environmental Psychology 24(3): 267-277.

Nisbet, M., and C. Mooney. 2007. Framing science. Science 316: 56.

NVivo. 2009. NVivo qualitative data analysis software; QSR International Pty Ltd. Version 9.

Osmond, D., N. Nadkarni, C. Driscoll, E. Andrews, A. Gold, S. Allred, A. Berkowitz, M. Klemens, T. Loecke, M.A. McGarrry, K. Schwarz, M. Washington, and P. Groffman. 2010. The role of interface organizations in science communication and understanding. Frontiers in Ecology and the Environment 8(6): 306-313.

Pielke, R.A. 2007. The honest broker: Making sense of science in policy and politics. Cambridge: Cambridge University Press.

Poliakoff, E., and T.L. Webb. 2007. What factors predict scientists' intentions to participate in public engagement of science activities? Science Communication 29(2): 242-263.

Rabinovich, A., and T. Morton. 2012. Unquestioned answers or unanswered questions: Beliefs about science guide responses to uncertainty in climate change risk communication. Risk Analysis 32(6): 992-1002.

Rubin, H., and I. Rubin. 1995. Qualitative interviewing: The art of hearing data. Thousand Oaks, CA: Sage.

Singh, G., J. Tam, T. Sisk, S. Klain, M. Mach, R. Martone, and K. Chan. 2014. A more social science: Barriers and incentives for scientists engaging in policy. Frontiers in Ecology and the Environment 3(12): 161-166.

Slimak, M.W., and T. Dietz. 2006. Personal values, beliefs, and ecological risk perception. Risk Analysis 26(6): 1689-1705.

Sturgis, P., and N. Allum. 2004. Science in society: Re-evaluating the deficit model of public attitudes. Public Understanding of Science 13: 55-74.

Walthall, C., et al. 2012. Climate change and agriculture in the United States: Effects and adaptation. USDA Technical Bulletin 1935. Washington DC: USDA.

Weber, E.U. 2010. What shapes perceptions of climate change? WIRE Climate Change 1: 332-342. 
Weinberg, A. 1985. Science and its limits. Issues in Science and Technology II 1: 59-72.

Weinberg, A. 1972. Science and trans-science. Minerva 10: 209-222.

Wilhere, G. 2011. Inadvertent advocacy. Conservation Biology 26(1): 39-46.

Wood, A.W. 1999. Kant's ethical thought. Cambridge: Cambridge University Press.

Wynne, B. 2006. Public engagement as a means of restoring public trust in science-hitting the notes, but missing the music? Community Genetics 9: 211-220.

Adam K. Wilke received his B.A. from the University of Minnesota, and M.S. from Iowa State University. He is currently a Ph.D. student at Iowa State University in the Department of Sociology and Graduate Program in Sustainable Agriculture. Mr. Wilke's interests include the human dimensions of agriculture and natural resource management, particularly the dissemination of scientific information for individual and collective decision making. His research involves the communication of climate science for agriculture and resource management.

Lois Wright Morton , Ph.D., received her Ph.D. in Development Sociology at Cornell University, Ithaca, New York. She is currently a Professor of Sociology in the College of Agriculture and Life Sciences at Iowa State University. Dr. Morton's areas of research include civic structure, social connections and human dimensions of natural resource management, performance-based agricultural environmental management in local watersheds, impacts of long term weather change on agricultural land use management, rural communities, and rural quality of life. Her most recent book, Pathways to Better Water Quality: The Citizen Effect (2011) focuses on farmerled watershed management and citizen solutions to agricultural nonpoint source pollution and represents a summary of her water quality research and extension work. 